\title{
Antistatic treatment and salbutamol dosing have variable effect on drug delivery of
}

\section{valved holding chambers}

Csonka Péter ${ }^{1,2}$, Lehtimäki Lauri ${ }^{3,4}$

${ }^{1}$ Centre for Child Health Research, Tampere University and Tampere University Hospital, Tampere, Finland;

${ }^{2}$ Terveystalo Healthcare, Tampere, Finland; ${ }^{3}$ Allergy Centre, Tampere University Hospital, Tampere, Finland;

${ }^{4}$ Faculty of Medicine and Health Technology, Tampere University, Tampere, Finland

Short title: Drug delivery of six valved holding chambers

Keywords: valved holding chamber; salbutamol; static charge; inhalation therapy; number of puffs 


\section{Abstract}

Aims: Our aim was to evaluate whether the number of puffs or antistatic treatment have significant effect on drug delivery of six different valved holding chambers (VHCs).

Methods: We used simulated paediatric breathing pattern with $25 / \mathrm{min}$ frequency and $200 \mathrm{ml}$ tidal volume. When comparing the effect of antistatic treatment, we used $100 \mu \mathrm{g}$ of salbutamol (one puff Ventolin Evohaler $100 \mu \mathrm{g} / \mathrm{dos}$ ) actuated into each VHC before and after detergent wash. When comparing the effect of one or two puffs (100 vs. $200 \mu \mathrm{g})$, all VHCs were washed prior to the measurements.

Results: All VHC were significantly affected by antistatic treatment. Washing improved drug delivery of four VHCs (1.3-2.2 fold increase in median filter dose) but had an opposite effect in two devices (54-61\% decrease). The effect of dose doubling resulted in a 2.03 to 2.93 fold increase on filter dose in two VHCs. Four out of the six VHC showed significantly poorer performance with two puffs as opposed to one puff (ratio of two puffs to one puff varied between 1.19-1.77).

Conclusion: VHCs marketed as antistatic are significantly affected by antistatic treatment. To ensure optimal drug delivery, salbutamol should be actuated to VHCs one puff at a time. Each VHC brand has its unique characteristic that affects drug delivery in a way that cannot be generalised to another VHC. There is a need for universal standardisation of VHCs.

Key Notes: Valved holding chambers (VHCs) that are marketed as antistatic are significantly affected by antistatic treatment. Multiple actuations before inhalation tend to decrease the drug delivery efficacy of VHCs. Each VHC brand has its unique characteristic that affects drug delivery in a way that cannot be generalised to another VHC. There is a need for comprehensive and financially independent testing and standardisation of VHCs. 


\section{Introduction}

In young children aerosolised medication is administered by pressurised metered dose inhalers (pMDIs). To improve pulmonary drug delivery it is recommended to use valved holding chambers (VHCs) since they preclude the need for coordination of actuation-inhalation from pMDI by holding the aerosol cloud to be released only during inhalation (1)'(2).Commercially available VHCs differ in material, electrostatic characteristics, volume, dead space, and valve properties. The behaviour of an aerosolised drug inside the chamber is dependent on all of the before mentioned factors as well as on the flow and turbulence created by the puff itself and breathing. Certainly, particular combinations of pMDI-VHC may result in remarkable differences in dose output $(3)^{\prime}(4)^{\prime}(5)^{\prime}(6)^{\prime}(7),(8),(9)$ and the effects of anti-static handling of the VHC and use of one or several puffs at a time have not been widely studied in different types of VHCs.

Due to the non-conducting nature of most plastic chambers electrostatic charge can be induced by frictional contact with a material of different dielectric constant. The actuated aerosol may be attracted to the chamber wall by the electrostatic charge and influence the delivery of aerosols (10),(11). Antistatic VHCs might thereby facilitate the output of aerosol with better particle size distribution compared to static devices [13].

A detergent is an anionic, cationic or non-ionic surfactant or a mixture of different surfactants usually used in dilute solutions. Depending on their composition, some are designed for dish washing at households while others are biologically more active and designed for professional hospital use. Ionic detergent coating of the VHC can significantly improve drug delivery rendering the device equivalent to VHC internally covered with a conducting material (10). Washing with common household detergents can also successfully reduce the static charge of plastic VHCs and thus improve both in vitro and in vivo drug delivery (12),(13),(14). However, the effect of the electrostatic charge is not always apparent. For example, Dompeling et al. (15) found that compared to an antistatic metal VHC certain static plastic VHCs were equally effective in bronchodilator response to salbutamol in children with asthma. In addition, detergent washing may confer variable and unpredictable anti-static effects upon some devices (5). 
Multiple actuations of the pMDI into the VHC prior to inhalation will not necessarily increase the drug dose available for inhalation as expected. In one study, multiple actuations of $100 \mu \mathrm{g}$ salbutamol decreased drug recovery per actuation by $22 \%$ for 2 actuations and by $62 \%$ for 5 actuations compared with inhalation after each single actuation. Thus, when five $100 \mu \mathrm{g}$ actuations were released into the VHC before inhalation, only $103 \mu \mathrm{m}$ were recovered in particles smaller than $5 \mu \mathrm{m}$, compared to a total of about $270 \mu \mathrm{g}$ if each actuation was inhaled separately (16). Multiple actuations resulted in decreased drug delivery in other studies also using different devices and molecules (13),(14),(17).

According to the GINA guidelines, plastic spacers should be pre-washed with detergent and air-dried before use bur for spacers made of anti-static materials the assumption is that they are less prone to be influenced by static charge (1). The same guideline also recommends that pMDI should be actuated one puff at a time into the VHC. The evidence for these recommendations is classified to be poor (level D). Neither is it well documented whether these recommendations are accurate for all VHCs.

Before guidelines and generalized recommendations on anti-static handling and use of one or several puffs at a time can be given, there is a need for more comprehensive understanding of the characteristics of each VHC used. We have previously shown marked variation in drug delivery capacity of several VHCs with different breathing patterns (7),(8). The aims of our present study were to evaluate the effect of antistatic treatment and the number of puffs on salbutamol delivery using six different VHC brands under standardized conditions. 


\section{Materials and method}

\subsection{Device setup}

The delivery of salbutamol generated by a pMDI (Ventoline Evohaler $1 \mathrm{mg} / \mathrm{mL}$, GlaxoSmithKline Inc., Evreux, France) was measured through six VHC brands (table 1). Two separate VHCs from different manufacturing lots were used for each brand.

A filter (PARI Respiratory Equipment, Inc., USA) within a low dead-space $(10 \mathrm{~mL})$ filter holder was used to trap the drug particles. The filter holder was positioned between the VHC mouth piece and the breathing simulator (Sinus Breathing Simulator; PARI, Starnberg, Germany) (figure 1). The simulator produced alternating inspirations and expirations with sinusoidal wave and a duty cycle (inspiratory proportion of the breathing cycle) of 0.5 . The accuracy of the breathing simulator was validated by Fluke VT305 Gas Flow Analyzer (Fluke Biomedical, USA). The breathing simulator was set to simulate a paediatric breathing pattern with respiratory rate $(\mathrm{RR})$ of $25 / \mathrm{min}$ and tidal volume $\left(\mathrm{V}_{\mathrm{T}}\right)$ of $200 \mathrm{~mL}$.

\subsection{Handling of the VHCs and Measurement protocols}

In setups without antistatic handling VHCs were used as they were taken out of their original packaging. Antistatic treatment was done by immersing all the $\mathrm{VHCs}^{\prime}$ components into lukewarm water with detergent (1:2000 dilution, Fairy Liquid, Proctor \& Gamble UK, Surrey, UK), rinsing under running tap water, and leaving to air-dry vertically (1).

The effect of static charge of VHCs was evaluated by delivering one puff $(100 \mu \mathrm{g})$ of salbutamol under two different conditions: 1) new VHC used as it was taken out of the box and 2) new VHC washed with detergent before measurements. When the effect of one or two puffs of salbutamol at a time was compared, all VHCs where detergent-treated before each measurement. 
Before each measurement sequence the pMDIs were primed by actuating those five times to waste. Before every actuation the pMDI was shaken vigorously five times. The pMDI was then inserted into the VHC and actuated immediately at the start of inhalation (18). Salbutamol was let to accumulate into the filter for eight breathing cycles that has been shown to be sufficient to empty even larger volume VHCs (1)' (18)'(19)' (20). The filters were sealed with Parafilm M (Bemis Company, Inc., Oshkosh, WI) until analysis of drug content.

\subsection{Filter analysis}

Drug particles deposited on the filters at each measurement protocol were recovered and analysed by highperformance liquid chromatography (HPLC) carried out by Emmace Consulting AB (Lund, Sweden). The HPLC method was based on internal standard methodology and the limit of quantitation (LOQ) was determined as the peak height corresponding to 10 times the noise level. The LOQ was $2 \mu \mathrm{g}$. The HPLC system (Agilent 1100)

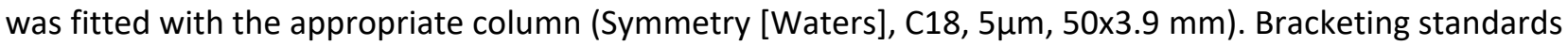
were made up and run, and the accuracy of the standards was checked. Standards were injected through the run at least 6 times. The percentage relative standard deviation of bracketing standards was $<2 \%$ throughout the run with excellent linearity $\left(y=0.0021 x, R^{2}=0.9998\right)$.

To assess how the results were affected by the possible variation in the output of pMDIs, we measured the emitted dose of each pMDI used in the study six times by connecting a filter directly to the mouthpiece of the pMDI. The median dose of salbutamol measured directly from the mouthpiece of the pMDIs was close to the nominal dose, with only a minor variation overall (median $91.8 \mu \mathrm{g}, 95 \%$ confidence interval [Cl] 89.7-93.9 $\mu \mathrm{g}$ ). 


\subsection{Statistics}

On the basis of our previous studies (7),(8) it was anticipated that nine measurements for each setting would allow detection of possible significant differences. The data was tested to be normally distributed. The in vitro filter dose values are reported as the medians with 95\% confidence interval (Cl). To test for the pairwise difference in in vitro filter dose the Mann-Whitney $U$ test was used. To assess the difference in ratios of two puffs to one puff (mean of 2 puffs divided by mean of 1 puff) with $95 \%$ confidence interval the method of Fieller was used. The software IBM SPSS Statistics for Windows, version 25 (IBM Corp., Armonk, N.Y., USA) was used for the data analysis.

\section{Results}

\subsection{Effect of antistatic treatment}

Table 2 and figure 2 and shows drug delivery performance of six VHCs with and without antistatic treatment. Washing the device with detergent significantly increased the filter dose of salbutamol for Aerochamber Plus (AC), Optichamber Diamond (OD), Volumatic and Vortex. However washing the VHC reduced the delivered drug dose for $\mathrm{A} 2 \mathrm{~A}$ and Babyhaler.

\subsection{The effect of number of puffs actuated}

The effect of dose doubling (actuating two doses prior to inhalation) resulted in variable increase in salbutamol filter dose compared to one dose (Table 2 and figure 3). For four out of the six VHCs (Aerochamber, Optichamber, Volumatic and Vortex) drug delivery with two puffs was significantly less than twofold compared to one puff (figure 3). For Babyhaler the drug delivery after two puffs was not significantly 
different from twice the dose after one puff. Interestingly, for A2A the delivered dose after two puffs was significantly more than twice the dose of a single puff.

\section{Discussion}

All VHCs were significantly affected by antistatic treatment, but not similarly. After detergent washing the filter dose of salbutamol was increased in four VHCs but the washing had an opposite effect in two devices. Doubling the dose of salbutamol before respiration resulted in variable increase in filter dose. Four out of the six VHCs showed significantly poorer performance per puff when two puffs were actuated into the chamber compared to a single puff.

The literature is inconsistent regarding the effect of static charge on VHCs. In a previous study reducing the charge by coating the chamber surface with ionic detergent resulted in an increase of $50-70 \%$ in small $(<6.8$ pm) particle delivery from a large (10) as well as from five small volume plastic VHCs in vitro (17). However, in another study, washing a Volumatic VHC with plain water was as effective as an antistatic lining in reducing the effects of static charge on salbutamol delivery in vivo (13). Similarly, the study by Dompeling et al. (15) found that despite their difference in static properties, plastic VHCs (Aerochamber and Volumatic) and the metal Nebuchamber were equally effective regarding the clinical efficacy of salbutamol in children with asthma. In addition, contrarily to our results, Hatley et al. [19] found that the performance of the OD, when taken out of its original packaging and used for the first time, was not influenced by washing in soapy water.

As opposed to our study, Wildhaber found significant improvement in salbutamol delivery after ionic detergent treatment of Babyhaler (17). Another study by Anhøj et al. reported that the electrostatic charge in Babyhaler and Aerochamber VHCs reduces lung dose in children by more than two-fold (21). We detected a significant reduction in the performance of Babyhaler as well as of the A2A after detergent washing. One possible explanation is that different types of detergents have variable effect on the chamber surface and 
valves. Wildhaber and colleagues used Liquid Pyrogen that is a mildly alkaline detergent containing a blend of wetting agents and sequestrants formulated specifically for cleaning of medical instruments. Anhøj and colleagues used benzalkonium chloride, a cationic surfactant. We used domestic dish washing detergent that is a mixture of ionic and non-ionic surfactants. Domestic detergents have been previously shown to be a practical way to reduce static on plastic VHCs and to improve both in vitro and in vivo delivery (12). In our study, despite using exactly the same antistatic treatment for each VHC brand, the effect of washing on drug delivery showed remarkable variation between devices.

There are only a handful of published studies evaluating the effect of single versus multiple puffs of inhaled asthma medication actuated into the VHC. Clark and Lipworth (13) measured higher plasma salbutamol levels and greater systemic responses after single puffs from the VHC compared to either multiple puffs or single puffs with delayed inhalation. In accordance to our findings, both Volumatic and Babyhaler have been previously shown to be less effective with multiple actuations. Barry and O'Callaghan (16) found that using Volumatic, double actuation decreased drug recovery by $22 \%$ per actuation and quintuple actuation by $62 \%$ per actuation for particles less than $5 \mu \mathrm{g}$ of salbutamol compared with single actuation. Thus, when five 100 $\mu \mathrm{g}$ actuations were released into the $\mathrm{VHC}$, only $103 \mu \mathrm{m}$ were recovered in particles smaller than $5 \mu \mathrm{m}$. In the study by Wildhaber et al. (17) the total amount of salbutamol delivery from the Babyhaler was reduced by $16.6 \%$ per actuation for two puffs and by $21.7 \%$ per actuation for five puffs, respectively. In the same study the differences in drug delivery from the antistatically treated Babyhaler and the antistatic Nebuchamber for multiple actuations were less pronounced but still statistically significant. In addition to salbutamol, multiple actuations might have a negative effect on other drugs as well. A Study by Barry and O'Callahan (14) reported that the amount of budesonide available for inhalation from the Nebuhaler VHC is decreased by multiple actuations of the metered dose inhaler into the VHC prior to inhalation.

Although, the delivered dose with the A2A increased significantly with double actuation, it was still relatively low (14.3\% of nominal dose). The detected over twofold increase in delivered dose might be due to the change in the valve movement or aerodynamic environment within the VHC. 
The observed marked differences in the amount of salbutamol recovered from the filter using different brands of VHCs are in line with our previous findings (7),(8). Together with the previously published reports on antistatic treatment and dosing, our current data underlines the fact that each device has unique and poorly predictable properties. The performance and drug delivery capacity of one VHC cannot be extrapolated to another device, may it be similar in material or design.

Our results are limited to the in vitro model used. In vitro findings do not directly represent real life clinical response. Indeed, there are studies that did not show significant in vivo differences between devices with different electrostatic charge (22). Despite their scientific value, the interpretation of in vivo studies are challenging too. The effect of inhaled drug therapy can be significantly affected by poorly controllable factors, such as breathing patterns of children for example (8). Especially in small children during an acute asthma attack when tidal volume is low and the lung deposition is reduced, patients are likely to be at the steep part of the dose-response curve for bronchodilator efficacy of salbutamol. Because of the many poorly controllable elements of inhalation therapy, it is important to study and regulate those factors that can be more readily standardised, such as VHC maintenance and dosing. The advantages of using an in vitro setting are the possibility to make multiple repeated measures and to avoid patient related sources of error, which allows the properties of the devices themselves to be focused on. Also statistical power to detect differences between devices may be poorer in clinical studies compared to in vitro studies because of larger standard deviation in clinical studies due to patient related factors. Face masks were excluded from this study for the same reason.

Another possible limitation of this study is that we did not measure the actual electrostatic charge of the VHCs. However, all devices were handled and treated in the same manner. In addition, we wanted to use a practical procedure that can be reproduced readily in everyday clinical setting and at home (12). 


\section{Conclusions}

Even VHCs that are marketed as antistatic are significantly affected by antistatic treatment. Most devices seem to benefit from washing with household detergents prior to use. However, some VHC are affected negatively by washing suggesting that each VHC brand has its unique characteristic that affects drug delivery in a way that cannot be generalised to another VHC. Multiple actuations before inhalation tend to decrease the drug delivery efficacy of VHCs. To ensure optimal drug delivery, salbutamol should be actuated to VHCs one puff at a time, and this practice should be universally applied. There is a need for comprehensive and financially independent testing and standardisation of VHCs.

\section{Acknowledgements}

The test rig was borrowed form Philips Respironics, Tangmere, UK and the respiratory simulator was borrowed from Children's Hospital Falun, Dalarna, Sweden. We would like to thank Mikael Csonka for his practical help.

\section{Funding}

Foundation of the Finnish Anti-Tuberculosis Association. Research Foundation for Pulmonary Diseases. Tampere Tuberculosis Foundation. Väinö and Laina Kivi Foundation 


\section{References}

1. Global Strategy for Asthma Management and Prevention - updated 2018 [Internet]. Available from: https://ginasthma.org/gina-reports

2. Amirav I, Newhouse MT. Review of optimal characteristics of face-masks for Valved-Holding Chambers (VHCs). Pediatr Pulmonol 2008; 43:268-74.

3. Barry PW, O'Callaghan C. In vitro comparison of the amount of salbutamol available for inhalation from different formulations used with different spacer devices. Eur Respir J 1997; 10:1345-8.

4. Mitchell JP, Nagel MMWMM. In Vitro Performance Testing of Three Small Volume-Holding Chambers under Conditions That Correspond with Use by Infants and Small Children. J Aerosol Med 1997; 10:341-9. Available from: http://www.liebertonline.com/doi/abs/10.1089/jam.1997.10.341

5. Berg E, Madsen J, Bisgaard H. In vitro performance of three combinations of spacers and pressurized metered dose inhalers for treatment in children. Eur Respir J 1998; 12:472-6.

6. Janssens HM, Heijnen EMEW, De Jong VM, Hop WCJ, Holland WPJ, De Jongste JC, et al. Aerosol delivery from spacers in wheezy infants: A daily life study. Eur Respir J 2000; 16:850-6.

7. Csonka P, Lehtimäki L. Valved holding chamber drug delivery is dependent on breathing pattern and device design. ERJ Open Res 2019; 5:00158-2018. Available from:

http://openres.ersjournals.com/lookup/doi/10.1183/23120541.00158-2018

8. Csonka P, Lehtimäki L. In vitro drug delivery performance of five valved holding chambers with and without face masks. Pediatr Pulmonol 2019. Available from: https://doi.org/10.1002/ppul.24425

9. Häselbarth J, Svedmyr J. Paediatric in vitro models showed significant variations in fluticasone proprionate output from valved holding chambers. Acta Paediatr 2019:apa.14965. Available from: https://onlinelibrary.wiley.com/doi/abs/10.1111/apa.14965

10. Wildhaber JH, Devadason SG, Hayden MJ, James R, Dufty AP, Fox RA, et al. Electrostatic charge on a plastic spacer device influences the delivery of salbutamol. Eur Respir J 1996; 9:1943-6.

11. Wildhaber JH, Waterer GW, Hall GL, Summers QA. Reducing electrostatic charge on spacer devices and bronchodilator response. Br J Clin Pharmacol 2000; 50:277-80.

12. Piérart F, Wildhaber JH, Vrancken I, Devadason SG, Le Souëf PN. Washing plastic spacers in household detergent reduces electrostatic charge and greatly improves delivery. Eur Respir J 1999; 13:673-8.

13. Clark DJ, Lipworth BJ. Effect of multiple actuations, delayed inhalation and antistatic treatment on the lung bioavailability of salbutamol via a spacer device. Thorax 1996; 51:981-4.

14. Barry PW, O'Callaghan C, Callaghan CO, O'Callaghan C. The effect of delay, multiple actuations and spacer static charge on the in vitro delivery of budesonide from the Nebuhaler. Br J Clin Pharmacol 1995; 40:768.

15. Dompeling E, Oudesluys Murphy AM, Janssens HM, Hop W, Brinkman JG, Sukhai RN, et al. Randomised 
controlled study of clinical efficacy of spacer therapy in asthma with regard to electrostatic charge. Arch Dis Child 2001; 84:178-82.

16. Barry PW, O'Callaghan C. Multiple actuations of salbutamol MDI into a spacer device reduce the amount of drug recovered in the respirable range. Eur Respir J 1994; 7:1707-9.

17. Wildhaber JH, Devadason SG, Eber E, Hayden MJ, Everard ML, Summers QA, et al. Effect of electrostatic charge, flow, delay and multiple actuations on the in vitro delivery of salbutamol from different small volume spacers for infants. Thorax 1996; 51:985-8.

18. Berlinski A, von Hollen D, Hatley RHM, Hardaker LEA, Nikander K. Drug Delivery in Asthmatic Children Following Coordinated and Uncoordinated Inhalation Maneuvers: A Randomized Crossover Trial. J Aerosol Med Pulm Drug Deliv 2017; 30:182-9. Available from: http://online.liebertpub.com/doi/10.1089/jamp.2016.1337

19. Minh KT, von Hollen D, von Königslöw AJ, Nikander K, Janssens HM. An Instrumented Valved Holding Chamber with Facemask to Measure Application Forces and Flow in Young Asthmatic Children. J Aerosol Med Pulm Drug Deliv 2014; 27:S-55-S-62. Available from:

http://online.liebertpub.com/doi/abs/10.1089/jamp.2014.1129

20. Schultz A, Le Souef TJ, Venter A, Zhang G, Devadason SG, Le Souef PN. Aerosol Inhalation From Spacers and Valved Holding Chambers Requires Few Tidal Breaths for Children. Pediatrics 2010; 126:e1493-8. Available from: http://pediatrics.aappublications.org/cgi/doi/10.1542/peds.2010-1377

21. Anhøj J, Bisgaard H, Lipworth BJ. Effect of electrostatic charge in plastic spacers on the lung delivery of HFA-salbutamol in children. Br J Clin Pharmacol 1999; 47:333-6.

22. Dubus JC, Guillot C, Badier M. Electrostatic charge on spacer devices and salbutamol response in young children. Int J Pharm 2003; 261:159-64. 
Table 1. Characteristics of the valved holding chambers (VHC) studied.

\begin{tabular}{|c|c|c|c|}
\hline & VHC volume & $\begin{array}{l}\text { Chamber material } \\
\text { and static charge }{ }^{a}\end{array}$ & $\begin{array}{l}\text { Valve characteristics and additional } \\
\text { features }\end{array}$ \\
\hline A2A Spacer (A2A) & $210 \mathrm{~mL}$ & $\begin{array}{l}\text { acrylonitrile } \\
\text { butadiene styrene, } \\
\text { antistatic }\end{array}$ & $\begin{array}{l}\text { Internal circular unidirectional silicon valve, } \\
\text { aerosol pass through the valve centrally }\end{array}$ \\
\hline Aerochamber plus (AP) & $149 \mathrm{~mL}$ & $\begin{array}{l}\text { acrylonitrile } \\
\text { butadiene styrene, } \\
\text { antistatic }\end{array}$ & $\begin{array}{l}\text { Internal circular unidirectional silicon valve, } \\
\text { aerosol pass at the valve periphery, top } \\
\text { outside inspiratory indicator }\end{array}$ \\
\hline Babyhaler (BH) & $350 \mathrm{~mL}$ & $\begin{array}{l}\text { polycarbonate, } \\
\text { non-electrostatic }\end{array}$ & $\begin{array}{l}\text { Internal circular unidirectional silicon valve } \\
\text { hinged centrally, aerosol pass at the valve } \\
\text { periphery, additional top outside valve }\end{array}$ \\
\hline $\begin{array}{l}\text { Optichamber diamond } \\
\text { (OD) }\end{array}$ & $140 \mathrm{~mL}$ & $\begin{array}{l}\text { acrylonitrile } \\
\text { butadiene styrene, } \\
\text { antistatic }\end{array}$ & $\begin{array}{l}\text { Internal cone shaped unidirectional silicon } \\
\text { valve, aerosol pass through the valve } \\
\text { centrally, additional top outside expiratory } \\
\text { valve }\end{array}$ \\
\hline Volumatic & $750 \mathrm{~mL}$ & $\begin{array}{l}\text { polycarbonate, } \\
\text { non-electrostatic }\end{array}$ & $\begin{array}{l}\text { Internal rigid circular plastic valve, aerosol } \\
\text { pass at the valve periphery }\end{array}$ \\
\hline Vortex & $194 \mathrm{~mL}$ & $\begin{array}{l}\text { metal, reduced } \\
\text { static charge }\end{array}$ & $\begin{array}{l}\text { Internal cone shaped unidirectional silicon } \\
\text { valve, aerosol pass through the valve } \\
\text { centrally }\end{array}$ \\
\hline
\end{tabular}

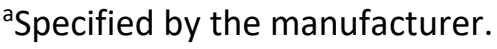


Table 2. The Effect of washing indicates in vitro filter dose $(\mu \mathrm{g})$ of salbutamol for VHCs with and without antistatic treatment. The effect of the number of puffs indicates in vitro filter dose $(\mu \mathrm{g})$ of salbutamol when actuating one or two puffs (100 or $200 \mu \mathrm{g}$ ) of salbutamol into the VHCs before activating the breath simulator and collecting the delivered drug. Breathing frequency, 25/min. Tidal volume, $200 \mathrm{ml}$. P-values, MannWhitney $\mathrm{U}$ test. To assess the difference in ratios of two puffs to one puff (mean of 2 puffs divided by mean of 1 puff) with $95 \%$ confidence interval the method of Fieller was used.

Effect of washing

\begin{tabular}{|c|c|c|c|c|c|c|}
\hline & Comparison & $\begin{array}{l}\text { Median } \\
(95 \% \mathrm{Cl}) \mu \mathrm{g}\end{array}$ & P-value & Comparison & $\begin{array}{l}\text { Median } \\
(95 \% \mathrm{Cl}) \mu \mathrm{g}\end{array}$ & $\begin{array}{l}\text { Ration of two } \\
\text { puffs to one puff } \\
(95 \% \mathrm{Cl})\end{array}$ \\
\hline A2A Spacer & $\begin{array}{l}\text { Not washed } \\
\text { Washed }\end{array}$ & $\begin{array}{l}23.5(18.5-27.4) \\
9.1(7.5-13.7)\end{array}$ & 0.002 & $\begin{array}{l}\text { One puff } \\
\text { Two puffs }\end{array}$ & $\begin{array}{l}9.1(7.5-13.7) \\
28.6(25.1-31.2)\end{array}$ & $2.93(2.36-3.81)$ \\
\hline $\begin{array}{l}\text { Aerochamber } \\
\text { plus }\end{array}$ & $\begin{array}{l}\text { Not washed } \\
\text { Washed }\end{array}$ & $\begin{array}{l}35.7(31.2-40.4) \\
47.9(37.0-52.4)\end{array}$ & 0.009 & $\begin{array}{l}\text { One puff } \\
\text { Two puffs }\end{array}$ & $\begin{array}{l}47.9(37.0-52.4) \\
71.5(63.8-81.2)\end{array}$ & $1.54(1.35-1.77)$ \\
\hline Babyhaler & $\begin{array}{l}\text { Not washed } \\
\text { Washed }\end{array}$ & $\begin{array}{l}6.9(5.8-8.5) \\
2.8(1.3-3.3)\end{array}$ & 0.002 & $\begin{array}{l}\text { One puff } \\
\text { Two puffs }\end{array}$ & $\begin{array}{l}2.8(1.3-3.3) \\
5.4(3.1-6.4)\end{array}$ & $2.03(1.43-2.85)$ \\
\hline $\begin{array}{l}\text { Optichamber } \\
\text { diamond }\end{array}$ & $\begin{array}{l}\text { Not washed } \\
\text { Washed }\end{array}$ & $\begin{array}{l}21.6(19.9-24.1) \\
41.0(37.2-48.1)\end{array}$ & $<0.001$ & $\begin{array}{l}\text { One puff } \\
\text { Two puffs }\end{array}$ & $\begin{array}{l}41.0(37.2-48.1) \\
72.0(68.8-75.1)\end{array}$ & $1.74(1.59-1.90)$ \\
\hline Volumatic & $\begin{array}{l}\text { Not washed } \\
\text { Washed }\end{array}$ & $\begin{array}{l}7.5(6.5-10.5) \\
12.5(7.3-22.3)\end{array}$ & 0.026 & $\begin{array}{l}\text { One puff } \\
\text { Two puffs }\end{array}$ & $\begin{array}{l}12.5(7.3-22.3) \\
13.7(9.5-23.1)\end{array}$ & $1.19(0.73-1.96)$ \\
\hline Vortex & $\begin{array}{l}\text { Not washed } \\
\text { Washed }\end{array}$ & $\begin{array}{l}27.1(21.2-42.0) \\
58.7(53.3-61.2)\end{array}$ & 0.002 & $\begin{array}{l}\text { One puff } \\
\text { Two puffs }\end{array}$ & $\begin{array}{l}58.7(53.3-61.2) \\
101.0(93.5-110.5)\end{array}$ & $1.77(1.62-1.92)$ \\
\hline
\end{tabular}

\section{Effect of the number of puffs}

Ration of two puffs to one puff

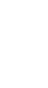


Figure 1. Test rig.

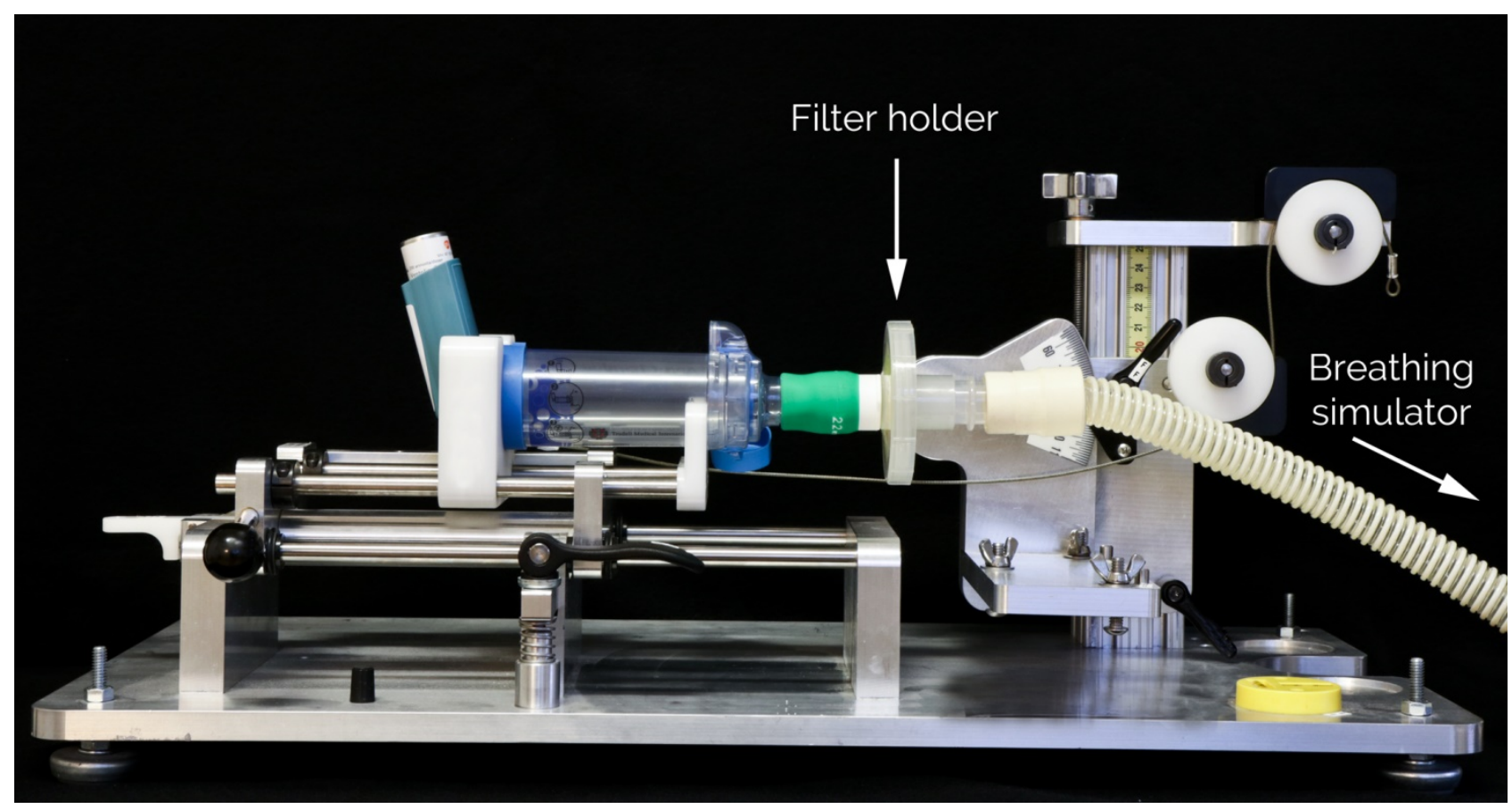


Figure 2. In vitro filter dose $(\mu \mathrm{g})$ of salbutamol for VHCs with and without antistatic treatment using breathing frequency of $25 / \mathrm{min}$ and tidal volume of $200 \mathrm{ml}$. The boxes present medians, $1^{\text {st }}$ and 3 rd quartile, minimum and maximum values, and outliers. P-values from Mann-Whitney $\mathrm{U}$ test between washed and not washed VHC.

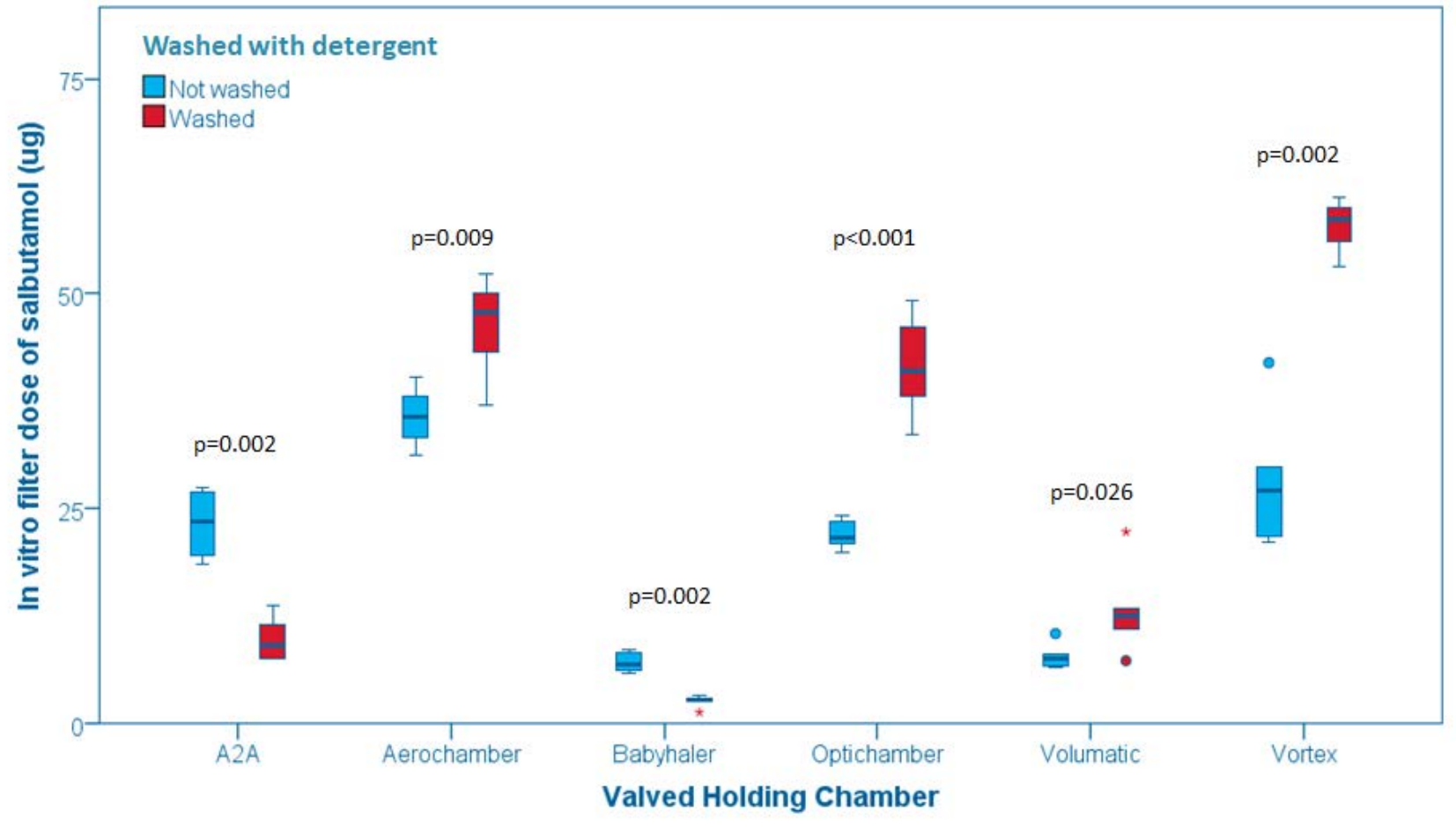


Figure 3. In vitro filter dose $(\mu \mathrm{g})$ of salbutamol when actuating one or two puffs (100 or $200 \mu \mathrm{g}$ ) of salbutamol into the VHCs before activating the breath simulator and collecting the delivered drug (breathing frequency of $25 / \mathrm{min}$ and tidal volume of $200 \mathrm{ml}$ ). The boxes present medians, $1^{\text {st }}$ and $3^{\text {rd }}$ quartiles, minimum and maximum values, and outliers. Numerical values above bars are the ratios of drug dose after two puffs to one puff (mean of 2 puffs divided by mean of 1 puff) with $95 \%$ confidence interval $(\mathrm{Cl}$, computed by the method of Fieller).

*If the $\mathrm{Cl}$ for the ratio (2 puffs / 1 puff) does not contain the value 2.00 the drug dose after two puffs is significantly different from twice the dose after one puff (level of significance is $\leq 0.05$ ).

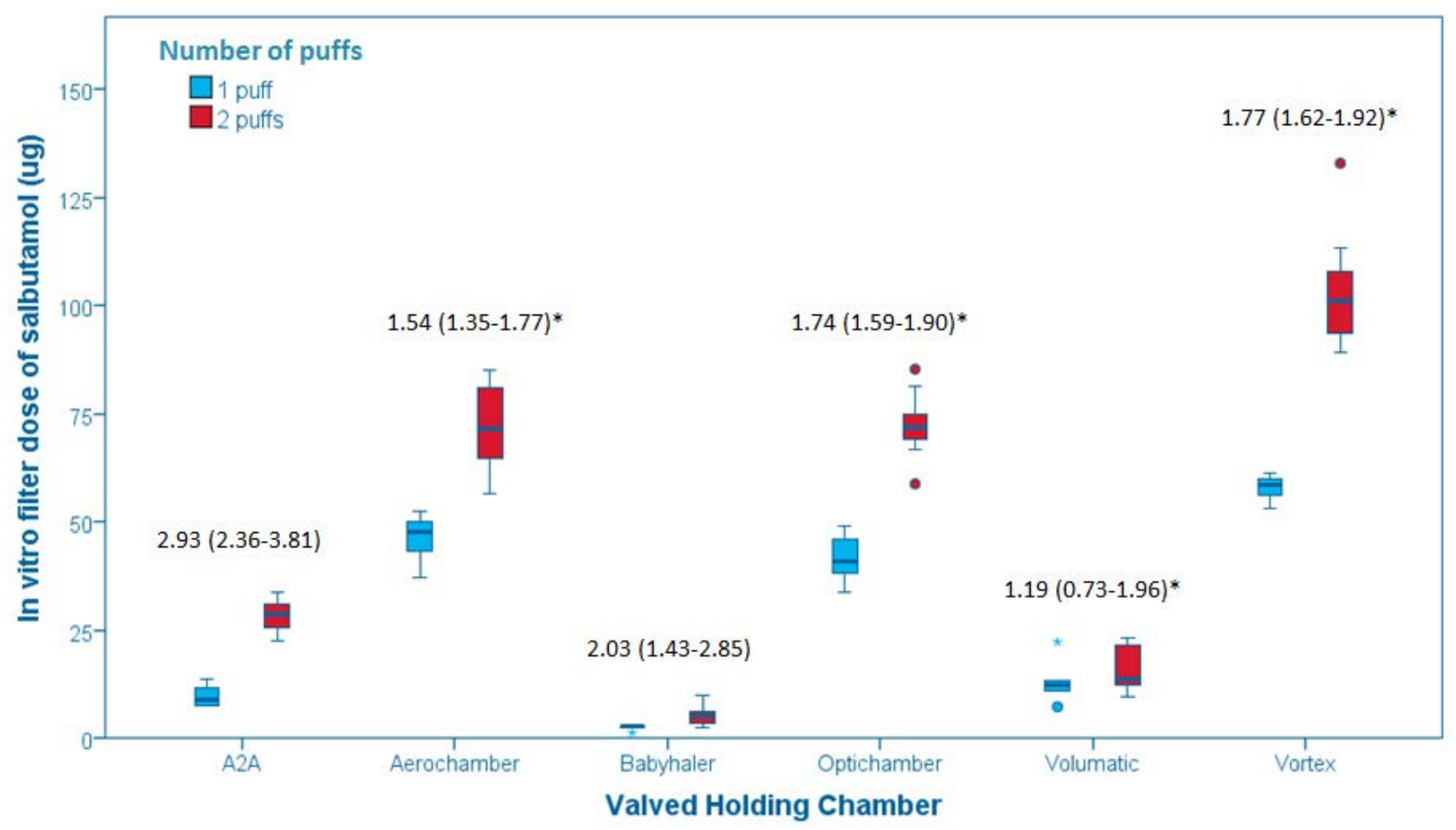

